Canadian

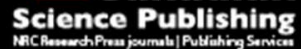

Canadian Journal of Physiology and Pharmacology Revue canadienne de physiologie et pharmacologie

\title{
Caffeine intake increases plasma ketones: an acute metabolic study in humans
}

\begin{tabular}{|c|c|}
\hline Journal: & Canadian Journal of Physiology and Pharmacology \\
\hline Manuscript ID & cjpp-2016-0338.R2 \\
\hline Manuscript Type: & Brief Report \\
\hline Date Submitted by the Author: & 07-Oct-2016 \\
\hline Complete List of Authors: & $\begin{array}{l}\text { Vandenberghe, Camille; Research Center on Aging; Universite de } \\
\text { Sherbrooke Faculte de medecine et des sciences de la sante, Pharmacology } \\
\text { \& Physiology } \\
\text { St-Pierre, Valerie; Research Center on Aging; Universite de Sherbrooke } \\
\text { Faculte de medecine et des sciences de la sante, Pharmacology \& } \\
\text { Physiology } \\
\text { Courchesne-Loyer, Alexandre; Research Center on Aging; Universite de } \\
\text { Sherbrooke Faculte de medecine et des sciences de la sante, Pharmacology } \\
\text { \& Physiology } \\
\text { Hennebelle, Marie; Research Center on Aging } \\
\text { Castellano, Christian-Alexandre; Research Center on Aging } \\
\text { Cunnane, Stephen; Research Center on Aging; Universite de Sherbrooke } \\
\text { Faculte de medecine et des sciences de la sante, Pharmacology \& } \\
\text { Physiology; Universite de Sherbrooke Faculte de medecine et des sciences } \\
\text { de la sante, Medicine }\end{array}$ \\
\hline Keyword: & $\begin{array}{l}\text { Ketones, Caffeine, Free fatty acids, Medium chain triglycerides, Alzheimer's } \\
\text { disease }\end{array}$ \\
\hline
\end{tabular}




\section{Caffeine intake increases plasma ketones: an acute metabolic study in humans}

Camille Vandenberghe ${ }^{1,2}$, Valérie St-Pierre ${ }^{1,2}$, Alexandre Courchesne-Loyer ${ }^{1,2}$, Marie

Hennebelle ${ }^{1}$, Christian-Alexandre Castellano ${ }^{1}$, Stephen C Cunnane ${ }^{1,2,3}$

${ }^{1}$ Research Center on Aging, Sherbrooke, CIUSSS de l'Estrie - CHUS, QC, Canada (CV, VSP, $\mathrm{ACL}, \mathrm{MH}, \mathrm{CAC}, \mathrm{SCC})$

${ }^{2}$ Department of Pharmacology \& Physiology, Université de Sherbrooke, Sherbrooke, QC, Canada (CV, VSP, ACL, SCC)

${ }^{3}$ Department of Medicine, Université de Sherbrooke, Sherbrooke, QC, Canada (SCC)

Author for correspondence: Stephen Cunnane

Research Center on Aging, 1036 Belvedere St. South, Sherbrooke, QC, Canada J1H 4C4

Tel: 1819 780-2220, ext 45670;

Stephen.Cunnane@USherbrooke.ca 


\section{ABSTRACT}

Brain glucose uptake declines during aging and is significantly impaired in Alzheimer's disease. Ketones are the main alternative brain fuel to glucose so they represent a potential approach to compensate for the brain glucose reduction. Caffeine is of interest as a potential ketogenic agent owing to its actions on lipolysis/ lipid oxidation but whether it is ketogenic in humans is unknown. This study aimed to evaluate the acute ketogenic effect of two doses of caffeine in healthy adults $(2.5 ; 5.0 \mathrm{mg} / \mathrm{kg})$ during a 4-hour metabolic study period. Caffeine given at breakfast significantly stimulated ketone production in a dosedependent manner $(+88 \% ;+116 \%)$ and also raised plasma free fatty acids. Whether caffeine has longterm ketogenic effects or could enhance the ketogenic effect of medium chain triglycerides remains to be determined.

Key words: Ketones; Ketonemia; Caffeine; Free fatty acids; Medium chain triglycerides; Lipolysis; Alzheimer's disease.

\section{RÉSUMÉ}

La consommation cérébrale de glucose diminue avec l'âge et, tout particulièrement, avec la maladie d'Alzheimer. L'élaboration de différentes stratégies nutritionnelles pour optimiser la production de cétones, le principal carburant alternatif cérébral, est nécessaire afin de soutenir les besoins énergétiques du cerveau vieillissant. La caféine est une molécule d'intérêt en raison de son action sur le métabolisme lipidique. L'effet aigu de différentes doses de caféine $(2.5 ; 5.0 \mathrm{mg} / \mathrm{kg})$ sur la production de cétones était évalué chez dix sujets. Nos résultats ont montré que la caféine ajoutée à un repas stimule significativement la cétonémie à des concentrations comparables à un jeûne de $12 \mathrm{~h}$ et cette réponse est dose-dépendante (+88 à $+116 \%)$. Ainsi, la prise de caféine combinée avec une source alimentaire cétogène comme les triglycérides à chaine moyenne dans le but de maximiser la cétonémie constitue une piste prometteuse d'intervention en concomitance avec d'autres traitements thérapeutiques dans un contexte de maladies neurodégénératives. 
INTRODUCTION

2

3 Caffeine upregulates metabolic rate (Miller et al. 1974), and stimulates energy expenditure. It is an adenosine receptor antagonist that increases sympathetic activity (Bellet et al. 1969) and inhibits cyclic nucleotide phosphodiesterase, which is responsible for catalyzing the conversion of cyclic adenosine monophosphate (cAMP) to AMP (Butcher et al. 1968; Quan et al. 2013). As a result, higher tissue concentrations of cAMP activate hormone-sensitive lipase and promote lipolysis (Acheson et al. 2004; Butcher et al. 1968). Free fatty acids (FFA) are the product of lipolysis and can be used as an immediate source of energy by many organs. They can also be converted by the liver into ketones (acetoacetate $[\mathrm{AcAc}], \beta$-hydroxybutyrate $[\beta-\mathrm{HB}]$ and acetone). Most organs use glucose and FFA as energy substrates. However, the brain is unable to use FFA for energy, and requires ketones as the principal alternative fuel to glucose (Cunnane et al. 2016). Plasma ketones are highly positively correlated to their utilization by the brain (Cunnane et al. 2016; Mitchell et al. 1995) and can provide up to $70 \%$ of brain's total energy during period of hypoglycaemia as, for example, during fasting (Owen et al. 1967).

Brain glucose uptake is $10-15 \%$ lower during normal aging (Nugent et al. 2014), and can be up to $35 \%$ lower in certain brain regions in neurodegenerative diseases such as Alzheimer's disease (AD) (Castellano et al. 2015). Several studies suggest that brain glucose hypometabolism potentially contributes to the onset and/or progression of AD (Cunnane et al. 2016; Mosconi et al. 2005; Nugent et al. 2014; Reiman et al. 2004; Schöll et al. 2011). A ketogenic supplement could therefore potentially help support the brain's energy needs during aging. Hence, the primary aim of this study was to evaluate whether the lipolytic effect of caffeine acutely increases plasma ketones in healthy adults during a fourhour metabolic study period. The secondary aim was to confirm whether caffeine increases FFA as previously reported (Acheson et al. 1980; Acheson et al. 2004).

\section{PARTICIPANTS AND METHODS}

\section{7}

\section{Participants}


29 Ethical approval for this study was obtained from the Research Ethics Committee of the Integrated

30 University Health and Social Services of the Eastern Townships - Sherbrooke University Hospital Center,

31 which oversees all human research done at the Research Center on Aging (Sherbrooke, QC, Canada). All

32 participants provided written informed consent prior to beginning the study. They underwent a screening

33 visit, including the analysis of a blood sample collected after a $12 h$ overnight fast. Exclusion criteria

34 included regular high consumption of caffeine (>300 mg/day), smoking, diabetes or glucose intolerance

35 (fasting glucose $>6.1 \mathrm{mmol} / \mathrm{L}$ and glycosylated hemoglobin $>6.0 \%$ ), untreated hypertension, dyslipidemia,

36 abnormal renal, liver, heart or thyroid function. This project is registered on ClinicalTrials.gov (NCT

37 02694601).

\section{Experimental design}

40 The protocol involved three randomized four-hour metabolic study days: a baseline metabolic day (CTL)

41 and two days each with a different dose of caffeine (2.5 mg/kg [C-2.5] and $5.0 \mathrm{mg} / \mathrm{kg}$ [C-5.0]). On each

42 metabolic study day, the participants arrived at 8:00 a.m. after $12 h$ of fasting and $24 h$ without caffeine

43 intake. At the time of signing the consent form, participants were aware of the $12 h$ fast and to abstain

44 from consuming caffeine. They also received a reminder call $24 h$ before the metabolic study day. A

45 forearm venous catheter was installed and blood samples were taken every 30 min during 4 hours. After

46 installing the catheter and the first blood sample, participants received a standard breakfast comprised of

47 two pieces of toast with raspberry jam, a piece of cheese, applesauce and $100 \mathrm{ml}$ of juice. The breakfast

48 contained 85 grams of carbohydrate, $9.5 \mathrm{~g}$ of fat and $14 \mathrm{~g}$ of protein. Commercially available caffeine

49 tablets (200 mg extra-strength Life Brand ${ }^{\mathrm{TM}}$, ON, Canada) were hand crushed to powder and two doses

50 were provided $(2.5 \mathrm{mg} / \mathrm{kg}$ and $5.0 \mathrm{mg} / \mathrm{kg})$ on separate test days. The low dose corresponding to $1 \frac{1}{2}$ cup of

51 coffee and the high dose to 3 cups of regular coffee, the highest quantity recommended by Heath

52 Canada. The caffeine dose to be given was mixed in $104 \mathrm{ml}$ of applesauce and consumed during

53 breakfast. No caffeine was added to the breakfast for CTL. Water was available ad libitum throughout the

54 study day. Blood samples were centrifuged at $3500 \mathrm{rpm}$ for $10 \mathrm{~min}$ at $4^{\circ} \mathrm{C}$ and plasma was stored at $-80^{\circ} \mathrm{C}$

55 until further analysis.

56 
Plasma analyses

59 Caffeine

60 Plasma caffeine was measured using a complete ELISA Kits from Neogen (WI, USA), according to the 61 manufacturers' protocol with the following modifications. Caffeine (Sigma-Aldrich ${ }^{\circledR}$, St-Louis, Mo, USA)

62 was diluted with the Neogen kit buffer (EIA) at multiple dilutions ending with the standard curve dilutions

63 from 0 to $25 \mathrm{ng} / \mathrm{ml}$. Plasma samples were then diluted with EIA buffer at a 1:50 000 dilution. Both

64 standards and samples were run in duplicate. The absorbance was then measured with a plate reader

65 (VICTOR, Perkin Elmer Inc, MA, USA) at $690 \mathrm{~nm}$.

66

$67 \quad$ Metabolites

68 Plasma glucose, lactate, triglycerides, total cholesterol (Siemens Medical Solutions USA, Inc., Deerfield,

69 IL, USA) and free fatty acids (Randox Laboratories Ldt, West Virginia, USA) were measured using

70 commercial kits on a clinical biochemistry analyzer (Dimension Xpand Plus, Siemens Healthcare

71 Diagnosis Inc., Deerfield, IL, USA) as previously described (Courchesne-Loyer et al. 2013). Plasma $\beta-H B$

72 and AcAc were evaluated by an automated colorimetric assay as previously described (Courchesne-Loyer

73 et al. 2013).

\section{Statistical analysis}

76 All results are given as mean \pm SEM. Ten participants were sufficient to meet the statistical power

$77 \quad(\beta=0.80)$ needed to observe a significant difference in plasma FFA with the caffeine supplementation

78 (Acheson et al. 1980). For lactate, metabolic study day values were normalized to baseline in order to

79 account for variability at the beginning of the study day. For post-caffeine ketone and FFA analysis, the

80 area under the curve (AUC) was calculated from 2 to 4-hour post-dose because that was when maximal

81 plasma caffeine was achieved. All statistical analyses were carried out using SPSS 23.0 software (SPSS

82 Inc., Chicago, IL, USA). Comparison of the three test conditions was done using the Friedman test, and

83 the effect of caffeine supplementation was determined in each group using a Wilcoxon's signed rank test. 
84 Differences were considered statistically significant at $p \leq 0.05$. Data were graphed using Prism version 6.0 85 (GraphPad Software Inc., San Diego, CA, USA).

\section{RESULTS}

88 Two men and eight women completed all three test conditions (Table 1). Participants were $33 \pm 19$ years

89 of age and had a body mass index of $24 \pm 8(n=10)$. The participant's baseline biochemical parameters 90 corresponded to normal references values from the Sherbrooke University Hospital Center (Sherbrooke,

91 Qc). No significant side effects were reported following caffeine intake. Baseline plasma caffeine values

92 did not significantly differ from zero on any of the three study days (Fig.1). There was no difference in

93 plasma glucose, triglycerides, or cholesterol response across the three metabolic days (data not shown).

94 Plasma lactate differed across the three metabolic days $(p=0.045)$, but after normalizing the data to 95 baseline, these differences disappeared $(p=0.607)$.

A dose-response was observed for plasma caffeine across the three metabolic days ( $p<0.05$; Fig. 1$)$.

98 Plasma caffeine significantly increased during the first hour post-dose $(p<0.05)$. C-2.5 increased plasma

99 caffeine to a maximum of $7.5 \pm 1.5 \mathrm{mg} / \mathrm{L}$ at $2 \mathrm{~h}$ and $\mathrm{C}-5.0$ increased plasma caffeine to a maximum of

$10010.0 \pm 2.3 \mathrm{mg} / \mathrm{L}$ at $3 \mathrm{~h}(p<0.05)$. No difference in plasma AcAc levels was observed across the three test

101 days ( $p=0.497$; Fig $2 \mathrm{~A}, 2 \mathrm{C})$. However, after normalizing the data to baseline, there was a significant group

102 difference between baseline and the two doses of caffeine at $3.5 h$, at which time AcAc was significantly

103 increased ( $p<0.05$; data not shown). A group difference was observed for the $\beta$-HB response from 2 to $4 h$

104 post-dose $(p<0.05$; Fig. 2B and 2D). Caffeine increased plasma $\beta$-HB by $88 \%$ and $116 \%$ in a dose-

105 dependent manner $(p<0.05)$. No significant difference in plasma FFA was observed during 0-2 $h$ post-

106 dose (Fig. 3A). Globally, FFA decreased from $711 \pm 398 \mu \mathrm{M}$ to $91 \pm 42 \mu \mathrm{M}$ during this period (Fig. 3A).

107 Between 2-4 $h$ after the breakfast, a dose-related increase of FFA was observed with the two doses of

108 caffeine $(p<0.005$; Fig. 3B). C-2.5 raised plasma FFA concentrations to $548 \pm 276 \mu \mathrm{M}$ after $4 h$ whereas

109 C-5.0 raised plasma FFA to $695 \pm 433 \mu \mathrm{M}$. 


\section{DISCUSSION}

113 This short-term study showed that caffeine intake can stimulate ketogenesis by increasing $\beta$-HB

114 concentrations by $88-116 \%$ with a maximum within four hours post-dose. A dose-response was observed

115 for plasma $\beta$-HB (Fig. 2D) but not for AcAc (Fig. 2C), which could be explained by the larger inter-group

116 variation in AcAc. The increase in plasma ketones obtained with these doses of caffeine could at least

117 transiently contribute to 5-6\% of brain energy needs (Cunnane et al. 2016).

118 The increased plasma FFA after caffeine seen in the present study confirms prior results (Acheson et al.

119 1980; Acheson et al. 2004; Bellet et al. 1968; Bellet et al. 1969). Caffeine competes for the adenosine

120 receptor, inhibits phosphodiesterase activity and increases plasma FFA. FFA entering the liver are beta-

121 oxidized and converted to ketones due to condensation of pairs of acetyl-CoA units as their availability

122 exceeds their utilization by the tricarboxylic acid cycle (Wang et al. 2014).

124 The increase in blood ketones shown here was equivalent to that observed after an overnight fast.

125 Another way of increasing blood ketones is to provide a source of medium-chain triglyceride (MCT)

126 (Courchesne-Loyer et al. 2013). Caffeine combined with an MCT supplement could potentially prolong

127 mild ketonemia. Such products are already available on the market although no reports are available on

128 the ketogenic effect of the combination of these products.

129 One limitation of this study design is that the metabolic study period was only 4 hours. However, this was

130 sufficient to observe an effect on plasma ketones and FFA within the period during which peak plasma

131 caffeine was observed. The half-life of caffeine is 4.5 hours, which suggests that its peak metabolic effect

132 would take place over 2-3 hours. Furthermore, the effect of each caffeine dose was only assessed once,

133 so a longer term study would be useful.

135 In conclusion, by enhancing lipolysis and increasing blood FFA levels, which in turn provide substrates for

136 ketogenesis, caffeine at doses of 2.5 and $5.0 \mathrm{mg} / \mathrm{kg}$ stimulated safe and mild ketonemia in healthy adults

137 to a ketone level twice that seen after an overnight fast. Several studies suggest that regular caffeine 
138 consumption may be linked to the decreased risk of developing late-life cognitive decline (Panza et al.

139 2015). Further studies are needed to evaluate caffeine's long term effect on ketonemia and its impact on

140 brain function during aging.

\section{ACKNOWLEDGMENTS}

143 We thank our research nurses, Conrad Filteau and Christine Brodeur-Dubreuil, for their assistance in 144 participant screening, blood sampling and care of the participants. SCC, CV and VSP designed the study. $145 \mathrm{CV}, \mathrm{VSP}, \mathrm{ACL}, \mathrm{CAC}$ and $\mathrm{MH}$ conducted the study. CV, VSP, CAC and SCC analyzed and interpreted the 146 data. All the authors contributed to the final article.

\section{REFERENCES}

Acheson, K. J., Zahorska-Markiewicz, B., Pittet, P., Anantharaman, K., and Jéquier, E. 1980. Caffeine and coffee: their influence on metabolic rate and substrate utilization in normal weight and obese individuals. Am. J. Clin. Nutr. 33(5): 989-997.

Acheson, K. J., Gremaud, G., Meirim, I., Montigon, F., Krebs, Y., Fay, L. B., et al. 2004. Metabolic effects of caffeine in humans: lipid oxidation or futile cycling? Am. J. Clin. Nutr. 79(1): 40-46.

Bellet, S., Kershbaum, A., and Finck, E. M. 1968. Response of free fatty acids to coffee and caffeine. Metabolism, 17(8): 702-707. doi:10.1016/0026-0495(68)90054-1.

Bellet, S., Roman, L., DeCastro, O., Kim, K. E., and Kershbaum, A. 1969. Effect of coffee ingestion on catecholamine release. Metabolism, 18(4): 288-291.

Butcher, R. W., Baird, C. E., and Sutherland, E. W. 1968. Effects of lipolytic and antilipolytic substances on adenosine 3',5'-monophosphate levels in isolated fat cells. J. Biol. Chem. 243(8): 1705-1712.

Castellano, C. A., Nugent, S., Paquet, N., Tremblay, S., Bocti, C., Lacombe, G., et al. 2015. Lower brain 18F-fluorodeoxyglucose uptake but normal 11C-acetoacetate metabolism in mild Alzheimer's disease dementia. J. Alzheimers Dis. 43(4): 1343-1353. doi: 10.3233/JAD-141074.

Courchesne-Loyer, A., Fortier, M., Tremblay-Mercier, J., Chouinard-Watkins, R., Roy, M., Nugent, S., et al. 2013. Stimulation of mild, sustained ketonemia by medium-chain triacylglycerols in healthy humans: estimated potential contribution to brain energy metabolism. Nutrition, 29(4): 635-640. doi: 10.1016/j.nut.2012.09.009.

Cunnane, S. C., Courchesne-Loyer, A., St-Pierre, V., Vandenberghe, C., Pierotti, T., Fortier, M., et al. 2016. Can ketones compensate for deteriorating brain glucose uptake during aging? Implications for the risk and treatment of Alzheimer's disease. Ann. N. Y. Acad. Sci. 1367(1): 12-20. doi: 10.1111/nyas.12999.

Miller, D. S., Stock, M. J., and Stuart, J. A. 1974. Proceedings: The effects of caffeine and carnitine on the oxygen consumption of fed and fasted subjects. Proc. Nutr. Soc. 33(2): 28A-29A. 
Mitchell, G. A., Kassovska-Bratinova, S., Boukaftane, Y., Robert, M. F., Wang, S. P., Ashmarina, L., et al. 1995. Medical aspects of ketone body metabolism. Clin. Invest. Med. 18(3): 193-216.

Mosconi, L., Herholz, K., Prohovnik, I., Nacmias, B., De Cristofaro, M. T., Fayyaz, M., et al. 2005. Metabolic interaction between ApoE genotype and onset age in Alzheimer's disease: implications for brain reserve. J. Neurol. Neurosurg. Psychiatry, 76(1): 15-23. doi: 10.1136/jnnp.2003.030882.

Nugent, S., Tremblay, S., Chen, K. W., Ayutyanont, N., Roontiva, A., Castellano, C. A., et al. 2014. Brain glucose and acetoacetate metabolism: a comparison of young and older adults. Neurobiol. Aging, 35(6): 1386-1395. doi: 10.1016/j.neurobiolaging.2013.11.027.

Owen, O. E., Morgan, A. P., Kemp, H. G., Sullivan, J. M., Herrera, M. G., and Cahill, G. F. 1967. Brain metabolism during fasting. J. Clin. Invest. 46(10): 1589-1595. doi: 10.1172/JCl105650.

Panza, F., Solfrizzi, V., Barulli, M. R., Bonfiglio, C., Guerra, V., Osella, A., et al. 2015. Coffee, tea, and caffeine consumption and prevention of late-life cognitive decline and dementia: a systematic review. $J$. Nutr. Health Aging, 19(3): 313-328. doi: 10.1007/s12603-014-0563-8.

Quan, H. Y., Kim, D. Y., and Chung, S. H. 2013. Caffeine attenuates lipid accumulation via activation of AMP-activated protein kinase signaling pathway in HepG2 cells. BMB Rep. 46(4): 207-212. doi: 10.5483/BMBRep.2013.46.4.153.

Reiman, E. M., Chen, K., Alexander, G. E., Caselli, R. J., Bandy, D., Osborne, D., et al. 2004. Functional brain abnormalities in young adults at genetic risk for late-onset Alzheimer's dementia. Proc. Natl. Acad. Sci. U.S.A. 101(1): 284-289. doi: 10.1073/pnas.2635903100.

Schöll, M., Almkvist, O., Bogdanovic, N., Wall, A., Långström, B., Viitanen, M., et al. 2011. Time course of glucose metabolism in relation to cognitive performance and postmortem neuropathology in Met146Val PSEN1 mutation carriers. J. Alzheimers Dis. 24(3): 495-506. doi: 10.3233/JAD-2011-101563.

Wang, S. P., Yang, H., Wu, J. W., Gauthier, N., Fukao, T., and Mitchell, G. A. 2014. Metabolism as a tool for understanding human brain evolution: lipid energy metabolism as an example. J. Hum. Evol. 77: 41-49. doi: 10.1016/j.jhevol.2014.06.013. 
148 Table 1. Baseline demographic and biochemical parameters of the participants

149 (Mean \pm SEM)

150

\begin{tabular}{lccc}
\hline Characteristics & & & \\
\hline Age $(\mathrm{y})$ & 33 & \pm & 19 \\
Men/Women & $2 / 8$ & & \\
Weight $(\mathrm{kg})$ & 65 & \pm & 14 \\
Height $(\mathrm{cm})$ & 163 & \pm & 16 \\
Body mass index $\left(\mathrm{kg} / \mathrm{m}^{2}\right)$ & 24 & \pm & 8 \\
Glucose $(\mathrm{mmol} / \mathrm{L})$ & 4.2 & \pm & 0.4 \\
Lactate $(\mathrm{mmol} / \mathrm{L})$ & 1.86 & \pm 1.0 \\
Glycated hemoglobin $(\%)$ & 5.3 & \pm & 0.3 \\
Total cholesterol $(\mathrm{mmol} / \mathrm{L})$ & 4.3 & \pm & 0.8 \\
Triacylglycerol $(\mu \mathrm{mol} / \mathrm{L})$ & 749 & \pm 282 \\
Free fatty acids $(\mu \mathrm{mol} / \mathrm{L})$ & 711 & \pm 392 \\
Ketones $(\mu \mathrm{mol} / \mathrm{L})$ & 175 & \pm 65
\end{tabular}

151 
152 Figure 1. Plasma caffeine concentrations during the control (CTL) metabolic study day $(\bullet)$, after receiving 153 a $2.5 \mathrm{mg} / \mathrm{kg}(\mathrm{C}-2.5)(\square)$ or $5.0 \mathrm{mg} / \mathrm{kg}$ dose of caffeine (C-5.0) ( $\nabla)$. Arrow indicates breakfast. Values are

154 presented as mean $\pm \operatorname{SEM}(n=10 /$ point); * $p<0.05$ CTL vs C-2.5, $\uparrow p<0.05$ CTL vs C-5.0, \# $p<0.05$ C-2.5 155 vs C-5.0.

156

157 Figure 2. Plasma acetoacetate $[A]$ and $\beta$-hydroxybutyrate $[B]$ concentrations during the control $(C T L)$

158 metabolic study day $(\bullet)$, and after receiving a $2.5 \mathrm{mg} / \mathrm{kg}(\mathrm{C}-2.5)(\square)$ or $5.0 \mathrm{mg} / \mathrm{kg}$ dose of caffeine (C-5.0)

$159(\nabla)$. Arrow indicates breakfast. The area under the curve was measured from 2 to 4 -hour post-dose for

160 acetoacetate [C] and $\beta$-hydroxybutyrate [D]. Values are presented as mean $\pm \operatorname{SEM}(n=10 /$ point);

$161 * p<0.05$ CTL vs C-2.5, † $p<0.05$ CTL vs C-5.0, \# $p<0.05$ C-2.5 vs C-5.0.

163 Figure 3. Plasma free fatty acids (FFA) concentrations $[A]$ during the control (CTL) metabolic study day

164 obtained before $(\bullet)$, after receiving a $2.5 \mathrm{mg} / \mathrm{kg}$ dose $(C-2.5)(\square)$ or $5.0 \mathrm{mg} / \mathrm{kg}$ dose of caffeine $(C-5.0)(\nabla)$. 165 Arrow indicates breakfast. The area under the curve [B] was measured from 2 to 4-hour post-dose. Values 166 are presented as mean $\pm \operatorname{SEM}(n=10 /$ point $) ;{ }^{*} p<0.05$ CTL vs $C-2.5, \dagger p<0.05$ CTL vs C-5.0, \# $p<0.05$ C1672.5 vs C-5.0. 


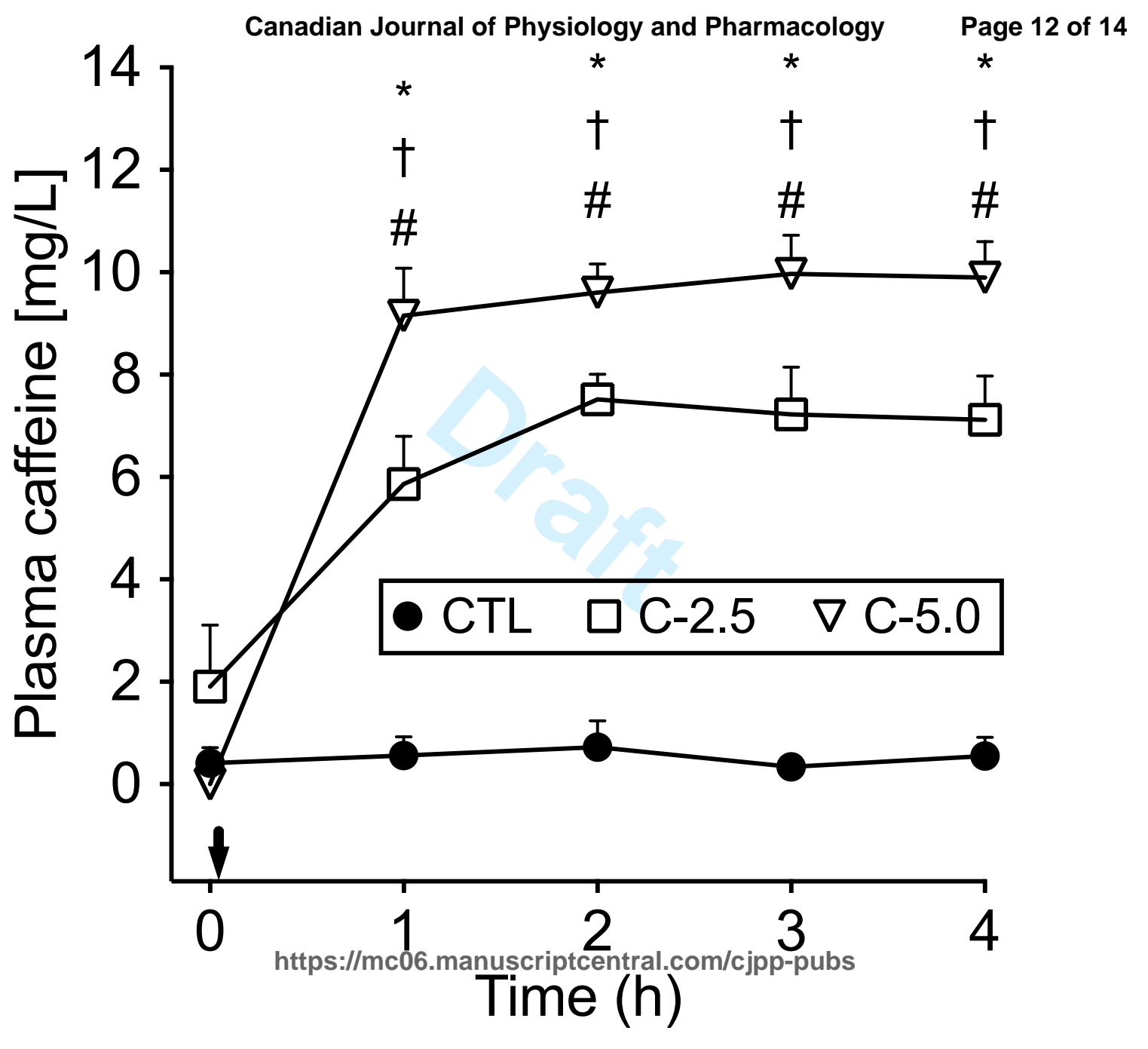



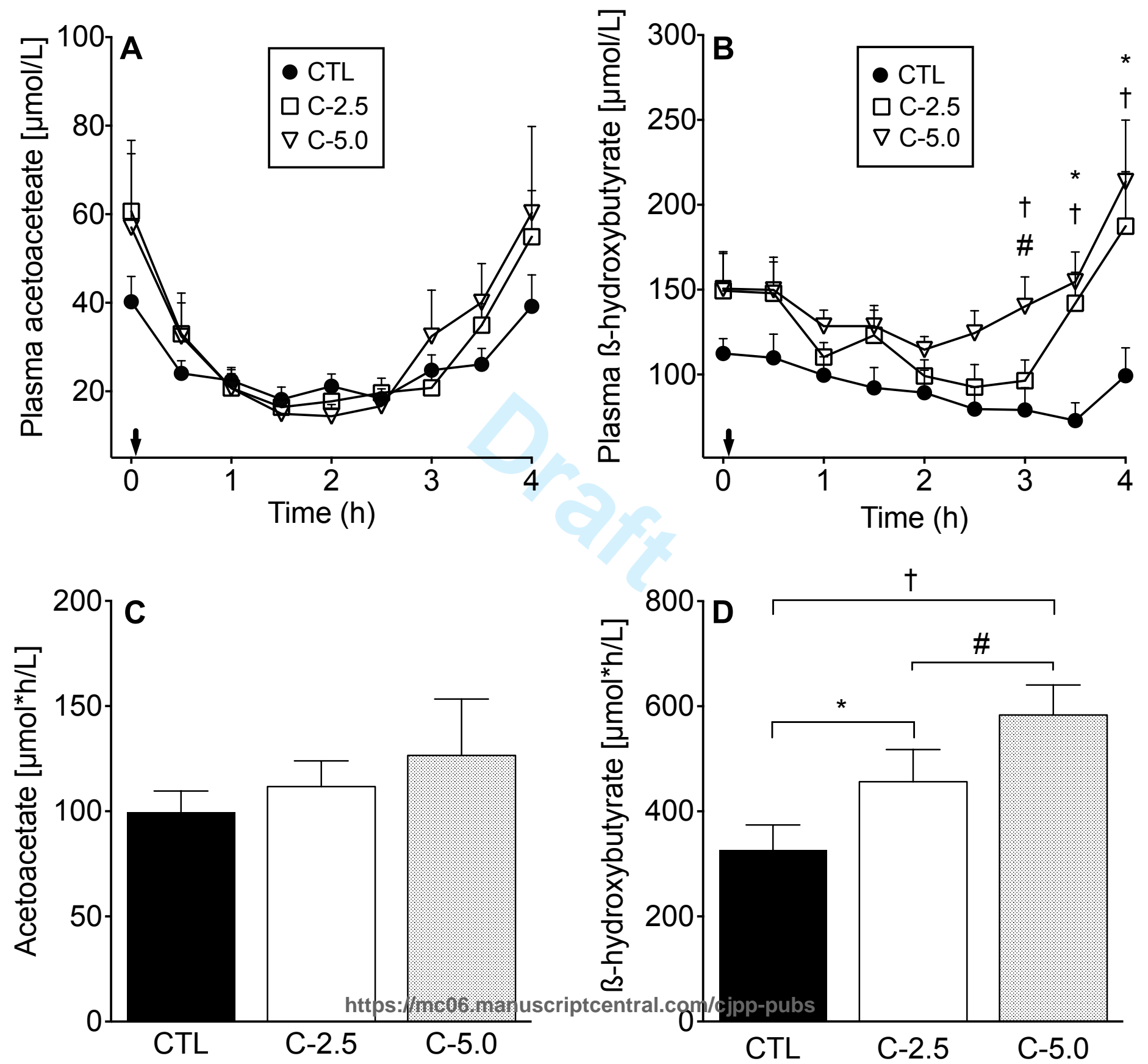

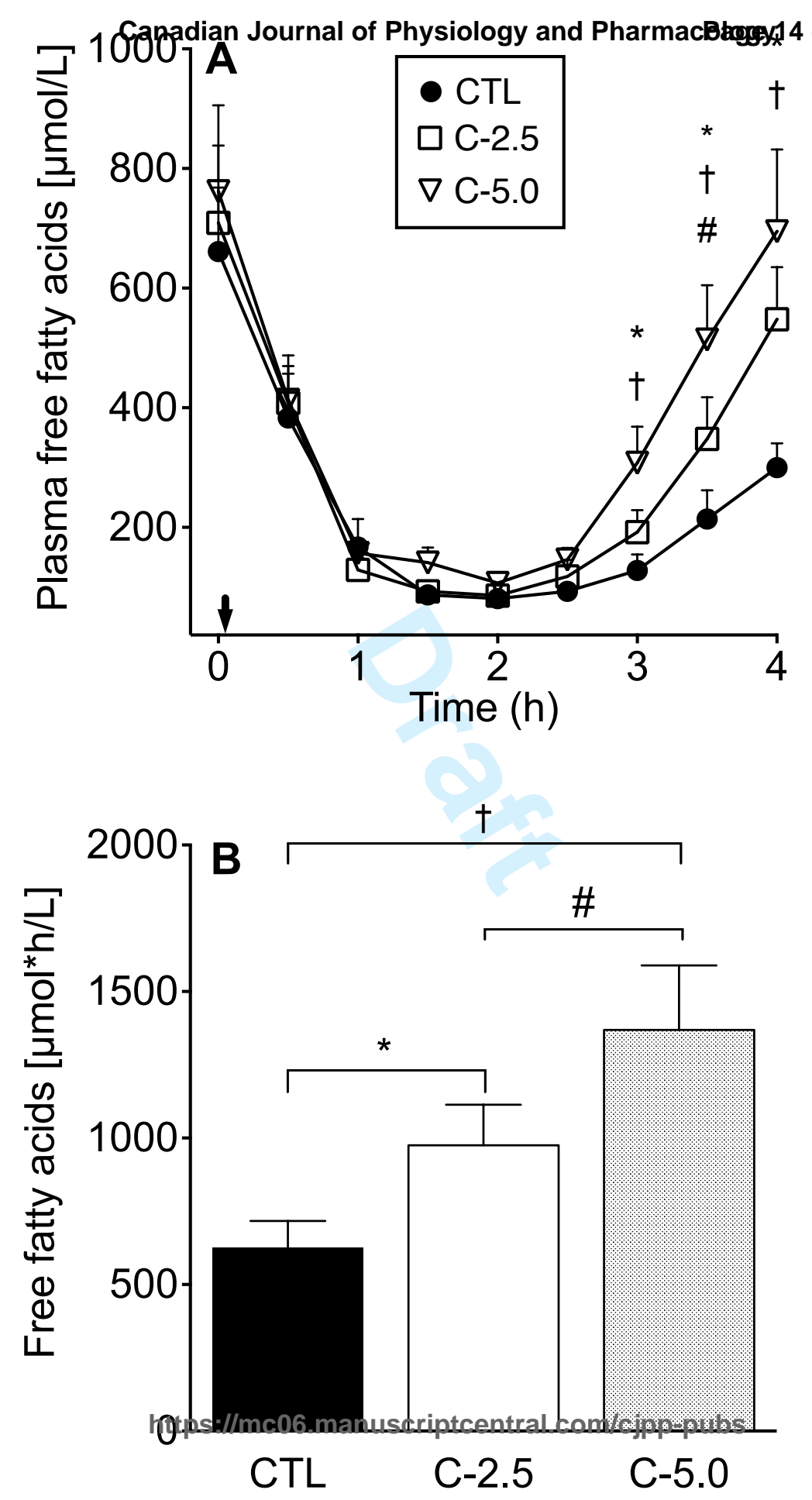